\title{
Postoperative abdominal wound infection - epidemiology, risk factors, identification, and management
}

This article was published in the following Dove Press journal:

Chronic Wound Care Management and Research

22 September 2015

Number of times this article has been viewed

\author{
Saïd C Azoury' \\ Norma Elizabeth Farrow ${ }^{2}$ \\ Qing L Hu ${ }^{2}$ \\ Kevin C Soares' \\ Caitlin W Hicks' \\ Faris Azar' \\ Nelson Rodriguez-Unda ${ }^{3}$ \\ Katherine E Poruk' \\ Peter Cornell' \\ Karen K Burce' \\ Carisa M Cooney ${ }^{3}$ \\ Hien T Nguyen' \\ Frederic E Eckhauser' \\ 'Department of Surgery, The Johns \\ Hopkins Hospital, Baltimore, MD, \\ USA; ${ }^{2}$ School of Medicine, Johns \\ Hopkins University, Baltimore, MD \\ USA; ${ }^{3}$ Department of Plastic and \\ Reconstructive Surgery, The Johns \\ Hopkins Hospital, Baltimore, MD, USA
}

Correspondence: Frederic E Eckhauser School of Medicine, The Johns Hopkins Hospital,The Johns Hopkins University School of Medicine, 600 NWolfe Street, Hospital Main Entrance - Sheikh Zayed

Tower, Baltimore, MD 2 I 287, USA

Tel + l 4l0 5020932

Email feckhau2@jhmi.edu

\begin{abstract}
Surgical site infections (SSIs) complicate the postoperative course of a significant proportion of general abdominal surgical patients and are associated with excessive health care costs. SSIs increase postoperative morbidity and mortality, and may require hospital admission, intravenous antibiotics, and even surgical reintervention. Risks associated with SSIs are related to both host and perioperative factors. However, a vast majority of these infections are preventable. More recently, quality initiative programs such as American College of Surgeons National Surgical Quality Improvement Program are expanding their roles to help better monitor adherence to improvement measures. Indeed, standardizing preoperative antibiotic prophylaxis timing is perhaps the most persuasive example and this has been integral to reducing postoperative SSI rates. Herein, the authors provide an update on the epidemiology, risk factors, identification, and management of wound infections following abdominal surgery.
\end{abstract}

Keywords: surgical site infection, diagnosis, treatment, prevention

\section{Introduction}

Postoperative wound infections, also known as surgical site infections (SSIs), complicate the recovery course of many patients. As defined by the Centers for Disease Control and Prevention (CDC), these infections typically occur within 30 days of an operation at the site or part of the body where the surgery took place, or within a year if an implant is left in place and the infection is thought to be secondary to surgery. ${ }^{1-3}$ Bacterial colonization on the patient's skin and alimentary and genital tract are the principal contributing sources that lead to SSIs. ${ }^{4}$ The organism most often isolated is Staphylococcus aureus. ${ }^{5}$ Exogenous sources, such as breaches in sterile technique and operating room equipment may contribute, albeit much less frequently than endogenous flora. ${ }^{6}$ Bacteria within the tissue or organ space hinder the postoperative healing processes, and can lead to anastomotic leaks, wound dehiscence, and superficial incisional infections.

SSIs may be classified as superficial/incisional if limited to the skin and subcutaneous tissue, deep incisional when involving the fascia and muscle, or organ space when involving a body cavity (eg, abdominal cavity following gastrointestinal surgery)., ${ }^{2,3}$ Deep tissue and organ space SSIs are less frequently encountered than superficial SSIs, but are associated with greater morbidity/mortality, readmission rates, longer hospital stay, and increased overall hospital-associated costs when compared with superficial SSIs. ${ }^{7-9}$ Although the majority of SSIs are uncomplicated, others may be severe and more challenging to manage, such as necrotizing deep soft tissue infections. ${ }^{2,8}$ The latter often require extensive surgical debridement, multiple reoperations, and may 
even be life-threatening. ${ }^{10,11}$ The location and extent of the infection, as well as the patient's clinical condition, guide the management approach. ${ }^{2,10}$ For instance, in the setting of an implant, as in the case for a synthetic mesh in an infected wound, oftentimes explantation of the implant is required, which may add to the postoperative morbidity. Furthermore, appropriate antibiotic therapy is often necessary to achieve source control in such patients.

With the rising incidence and associated morbidity of SSIs, various studies have looked at ways to better optimize patients prior to surgery or improve surgical technique and management of patients during the recovery period in order to prevent SSIs. ${ }^{12,13}$ Data regarding a hospital's rate of SSIs are becoming increasingly used as outcome measures for assessing the quality of their surgical services. ${ }^{14,15}$ Employing methods that could reduce the incidence of SSI would significantly reduce patient morbidity and mortality while lessening the associated economic burden; this has become central to quality improvement initiatives. ${ }^{16}$ Herein, the authors provide an update on the epidemiology, risk factors, identification, and management of wound infections following abdominal surgery.

\section{Epidemiology and impact Incidence and trends}

Overall, it is estimated that SSIs occur following $1 \%-3.1 \%$ of all surgical procedures and account for approximately $2.0 \%$ of deaths due to health care-associated infections (HAIs). ${ }^{2,7,17-20}$ With regard to abdominal surgery, the rate of wound infection may be much higher, with several prospective studies reporting an incidence of $15 \%-25 \%$ depending on the level of contamination. ${ }^{21-24} \mathrm{~A}$ recent study reviewing the reasons for hospital admissions after surgery in the USA demonstrated that SSI was the most common reason for unplanned readmission (19.5\% overall, $25.8 \%$ following colectomy/proctectomy) followed by obstruction/ileus (10.3\% overall). ${ }^{25}$ When considering HAIs, survey data gathered by 183 acute-care hospitals in 2011 estimated that 157,500 of 721,800 (21.8\%) cases were SSIs. ${ }^{26}$ Compared to other common nosocomial infections, SSIs (21.8\%) and pneumonia (21.8\%) were the most commonly reported, followed by gastrointestinal $(17.1 \%)$, urinary tract (12.9\%), and bloodstream infections (10.0\%). ${ }^{26}$ The number of SSIs reported is likely an underestimate of the true incidence, as many are diagnosed in an outpatient setting or after discharge. ${ }^{2}$

In general, the rate of SSI for men appears to be higher than that of women across several studies. ${ }^{8,27-29}$ Also, the topic of SSI rate in the elderly is becoming an increasingly important area for research. As patients are living longer, the number of elderly patients undergoing general surgical procedures will certainly increase, and complications such as SSIs in patients aged $\geq 65$ years will become a more apparent issue for general surgeons. ${ }^{28,30}$ Although the relationship between increasing age and risk of SSI is complex, it is well known that related mortality rate, hospital stay, and health care-related costs for older patients with SSIs are greater than that for younger patients. ${ }^{28}$ The impact of age and sex on SSI risk will be discussed later in the text.

\section{Economic impact}

Health care costs associated with treating SSIs are exceedingly high. ${ }^{30-33}$ A study performed in Veterans Affairs Hospitals demonstrated a 1.43-fold relatively higher hospital cost for patients with an SSI (\$11,876 difference) than for patients without an SSI. ${ }^{32}$ Similar total excess costs $(\$ 10,497)$ have been reported for patients with SSIs from the American College of Surgeons National Surgical Quality Improvement Program (ACS-NSQIP) when compared to those without SSIs. ${ }^{29}$ Even more striking, data from the 2005 Healthcare Cost and Utilization Project National Inpatient Sample (HCUP NIS) highlighted that SSI extended hospital length of stay by nearly 10 days, and hospital-associated costs increased by approximately $\$ 20,842 .{ }^{18}$ Nationally, 91,613 readmissions due to SSIs were reported in 2005, and overall associated hospital costs exceeded $\$ 900$ million. ${ }^{18}$ Furthermore, from 1993 to 2005, the number of emergency department visits in the USA for skin and soft tissue infections (SSTIs) increased from 1.2 million to 3.4 million. Of all emergency department visits, SSTIs constituted $1.35 \%$ in 1993 , increasing to $2.98 \%$ in $2005 .{ }^{34} \mathrm{~A}$ separate study demonstrated that between 2000 and 2004, total hospital admissions increased by $29 \%$ for SSTIs. ${ }^{35}$ Similar trends are highlighted at the state level. In North Carolina, the most common HAIs are SSIs (73\%), and related costs approximated $87 \%-91 \%$ of the total HAIrelated expenditure. ${ }^{36}$ These excess costs are largely related to antimicrobial/drug treatment, interventions, and additional nursing care. ${ }^{37}$

\section{Risk factors}

Understanding the multitude of variables associated with the risk of SSI following general abdominal surgery allows patients and physicians to identify modifiable risk factors and to make changes in an attempt to optimize patients prior to surgery. Several factors have been shown to be linked with SSI rate following general surgery across studies including open surgical approach, smoking status, insulin-dependent 
diabetes, immunosuppression, wound contamination, American Society of Anesthesiologists (ASA) classification score $>2$, hypoalbuminemia, and prolonged operative time (Table 1). ${ }^{13,28,30,38-44}$ As an example, knowing that a patient has a clean-contaminated or contaminated wound may help guide a surgeon's preference for closure with a biologic prosthesis rather than synthetic mesh when reinforcement of the abdominal wall is necessary.

The National Nosocomial Infection Surveillance (NNIS) system risk score was developed and based on three factors: 1) American Society of Anesthesiologists preoperative score of $>3$; 2) wound classification as contaminated or dirty; and 3 ) operation lasting longer than 75 th percentile for that specific operation (Table 2). ${ }^{44}$ This same study demonstrated that the rate of SSIs increases along the spectrum for clean $(2.1 \%)$, clean-contaminated $(3.3 \%)$, contaminated $(6.4 \%)$, and dirty wound types (7.1\%) (Table 2). ${ }^{44}$ Furthermore, across all wound classification categories, the risk of postoperative SSI is greater with an increasing number of risk factors (Table 2). Broadly, the likelihood of developing a SSI depends on host and perioperative variables (Table 1).

\section{Host factors \\ Demographics}

Male sex has been shown to be associated with an increased SSI risk, ${ }^{27}$ particularly in the emergency setting. ${ }^{45,46}$ It is speculated that this may be in part due to the decreased collagen deposition after surgery in men with aging compared to women, which increases the possibility for wound breakdown, dehiscence, and bacterial contamination. ${ }^{47}$

Table I Factors associated with increased surgical site infection risk

\begin{tabular}{|c|c|}
\hline Host-related & Perioperative \\
\hline Advancing age, up to 65 years & $\begin{array}{l}\text { Inadequate surgical } \\
\text { scrub/skin preparation }\end{array}$ \\
\hline Diabetes mellitus & Preoperative shaving \\
\hline Obesity & $\begin{array}{l}\text { Inappropriate antimicrobial } \\
\text { prophylaxis }\end{array}$ \\
\hline Cancer & Prolonged operative time \\
\hline $\begin{array}{l}\text { Altered immune response (eg, HIVIAIDS, } \\
\text { immunosuppressive drugs) }\end{array}$ & $\begin{array}{l}\text { Poor operating room } \\
\text { ventilation }\end{array}$ \\
\hline Smoking/tobacco use & $\begin{array}{l}\text { Foreign body } \\
\text { (mesh, implants, prosthesis) }\end{array}$ \\
\hline Poor nutritional status, hypoalbuminemia & Need for blood transfusion \\
\hline Poor functional status & $\begin{array}{l}\text { Inadequate tissue } \\
\text { oxygenation }\end{array}$ \\
\hline Coexisting infection at nonsurgical site & Open technique \\
\hline Previous abdominal procedure & Poor aseptic technique \\
\hline $\begin{array}{l}\text { American Society of Anesthesiologists } \\
\text { classification score }>2\end{array}$ & $\begin{array}{l}\text { Tissue trauma } \\
\text { Contaminated or dirty wound }\end{array}$ \\
\hline
\end{tabular}

\section{Age}

The reported impact of age on SSI risk has been unclear, and the relationship is complex. While some researchers have observed an increased rate of infection in older patients, ${ }^{48}$ others have demonstrated lower associated SSI rates when compared to patients younger than 55 years. ${ }^{8,49}$ A more recent multi-institutional study demonstrated that increasing age, up to 65 years, independently predicted an increased risk of SSI. ${ }^{30}$ However, beyond that age, increasing age independently predicted a decreased risk of SSI. ${ }^{30}$ It is likely that the higher rate of comorbidities in aged patients is a confounding factor in the aforementioned relationship and certainly, this topic requires ongoing investigation.

\section{Wound classification}

The risk of SSI rises with increasing wound class as defined by the CDC (Table 2) ${ }^{44,50}$ One study observed a significantly increased risk of SSI in patients with wound class of $>2$ (contaminated or dirty-infected cases). ${ }^{8}$ This is not surprising, as the probability of developing a wound infection is greater with increases in bacterial load. However, the reported quantitative bacterial load at which this risk increases has varied across studies, with several sources estimating $>10^{4}-10^{5} \mathrm{CFU} / \mathrm{g} .^{51-55}$

\section{Functional and nutritional status}

Dependent functional status has been associated with higher SSI rates when compared to independent status. ${ }^{49}$ Furthermore, hypoalbuminemia is associated with an increased risk of postoperative SSI of any type, and therefore ensuring adequate preoperative nutritional support is essential for optimizing surgical outcomes. ${ }^{38}$

\section{Immunosuppression}

Use of steroids has been linked to the risk of SSI, although it is important to note that the underlying reason for which the patient is on steroid treatment may by itself increase the risk of SSI. ${ }^{13}$ For instance, some studies have associated history of COPD with increased SSI risk and many patients with COPD are on chronic steroid treatments. ${ }^{38}$ Additional studies are necessary to further elucidate these risk factors.

Drapeau et al reported a twofold higher rate of SSI in HIVinfected patients when compared to the general population. ${ }^{12}$ Furthermore, patients with lower preoperative CD4 counts are more likely to develop SSIs. ${ }^{56,57}$

\section{Comorbidities}

Patients with a body mass index (BMI) $\left(\mathrm{kg} / \mathrm{m}^{2}\right)$ in the normal range (18.5-24.9) have lower SSI rates when compared to 
Table 2 Wound class and risk of SSI by the NNIS system risk score

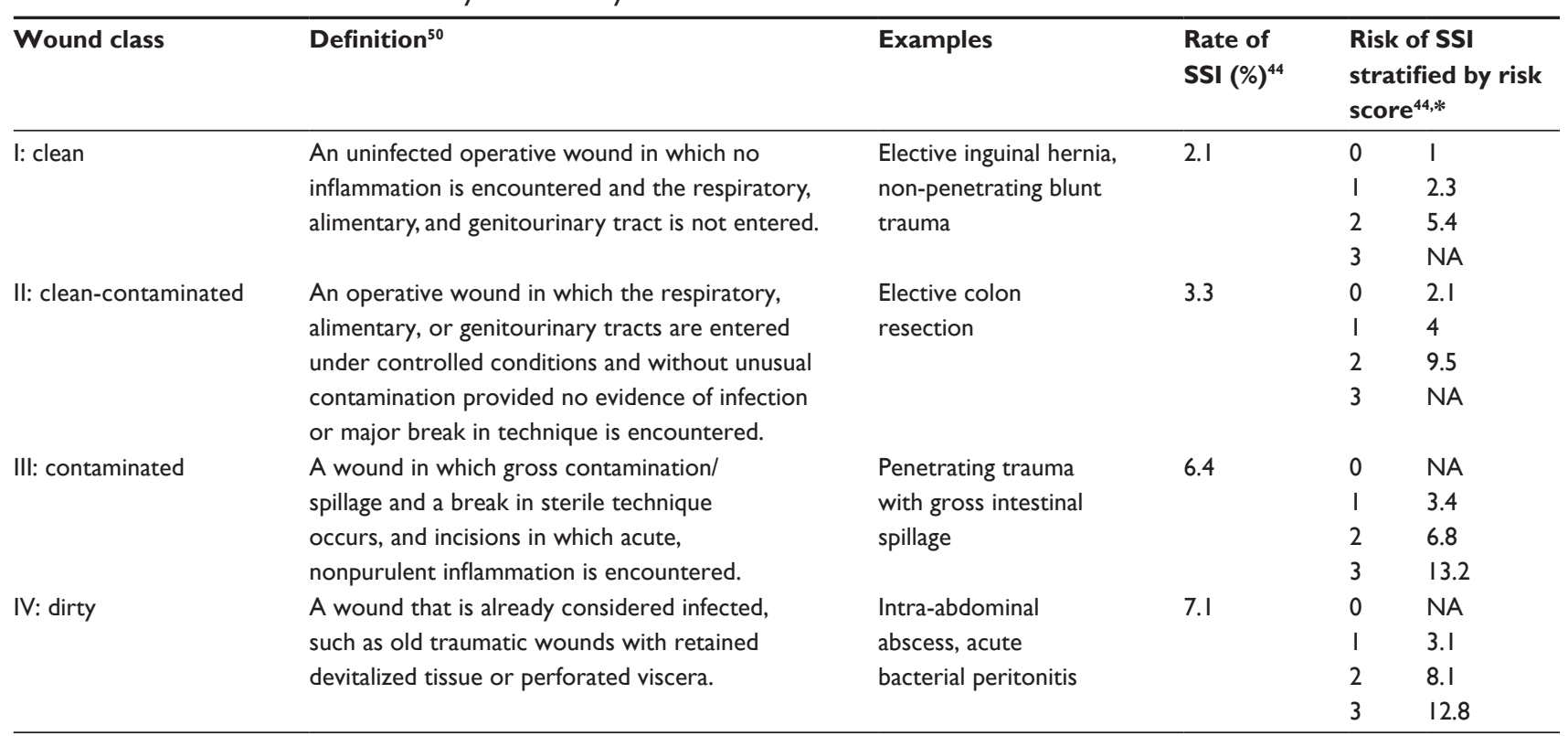

Notes: NNIS system risk score is the number of risk factors among these three: I) ASA scores 3, 4, or 5; 2) either contaminated or dirty operation; and 3) duration of surgery more than 75 th percentile for that specific procedure. *Note that a risk score of 0 is not possible with a contaminated or dirty wound classification.

Abbreviations: ASA, American Society of Anesthesiologists; NA, not applicable; NNIS, National Nosocomial Infection Surveillance; SSI, surgical site infection.

patients in the overweight and obese BMI categories. ${ }^{49} \mathrm{~A}$ BMI of $>30$ is associated with increased likelihood of developing a SSI, and this relationship strengthens with increasing BMI. ${ }^{8}$

Smoking decreases tissue oxygenation, which in turn increases the risk of wound infection. ${ }^{58,59}$ Whereas several studies have suggested that current smoking status (within a year of surgery) significantly increases the risk of all SSIs, others note an increase in deep/organ space infections, but not superficial SSIs. ${ }^{8,16,49}$

Preoperative sepsis is associated with developing an organ space SSI, but not superficial or deep infections. ${ }^{5}$ This is likely explained by resultant poor tissue perfusion/oxygenation, as well as bacterial spread from the bloodstream.

Previous abdominal surgery has been shown to be associated with increased risk of any SSI, including deep or organ space infections. ${ }^{24,38}$ For superficial SSIs, it is thought that the decreased vascularity of the prior scar and inherent problems related to prior wound healing complications may be the principle factors involved. ${ }^{38}$

\section{Perioperative factors Surgical technique}

Inadequate surgical scrub or antiseptic preparation, as well as shaving hair rather than clipping at the operative site, have been associated with SSI. ${ }^{5,48,60}$ Open surgical technique is associated with increased likelihood of developing SSI when compared to laparoscopic technique. ${ }^{8,49}$
Prolonged operative time increases the likelihood of developing SSI. ${ }^{8,49,61}$ One study noted that the likelihood of developing an SSI increases by $24 \%$ for each additional hour of operation. ${ }^{8}$ The association of prolonged operative duration and wound infection is complex and may not be entirely related to the operative time per se. Rather, this may signify a complex case or intraoperative complications, both of which have also been associated with SSI. ${ }^{49}$ Similarly, the association of preoperative anemia and blood transfusion with risk of SSI has been previously reported, but duration of the operation was a main confounding variable in this analysis. ${ }^{62}$

Emergency abdominal surgery presents a greater risk of postoperative wound infection than elective general surgery. ${ }^{13,45,63}$ Interestingly, factors contributing to the risk of SSI in elective and emergency cases are disparate. ${ }^{45}$ Following elective surgery, perioperative blood loss, smoking, operation type (eg, hernia versus colorectal surgery), and presence of comorbidities were shown to be independent predictors of wound complications and SSI. In contrast, following emergency surgery, variables including male sex, peritonitis, and multiple operations were associated with a higher likelihood of developing a SSI. ${ }^{45}$

\section{Risk factors by SSI type}

Increasing efforts are being made to separate superficial, deep incisional, and organ space infections when studying risk association in order to better identify and compare risk factors 
across studies and hospitals. ${ }^{38}$ Clinically, deep and organ space infections are associated with a longer length of stay, higher readmission rates, and overall morbidity when compared to superficial incisional infections. ${ }^{8}$ Interestingly, although some overlap exists, research has shown that the risk factors for superficial, deep, and organ space SSI may differ. ${ }^{8,49}$ A BMI $>25 \mathrm{~kg} / \mathrm{m}^{2}$, diabetes, alcohol use, vascular insufficiency, dyspnea and COPD increase the risk of superficial SSI. ${ }^{8,24,49}$ Factors associated with an increased risk of deep SSI include wound class $>2$, BMI $>25 \mathrm{~kg} / \mathrm{m}^{2}$, duration of operation, and ASA class $>2$, and those unique to organ space SSIs include weight loss $>10 \%$, disseminated cancer, prior surgery within 30 days, preoperative radiation, dialysis, and chronic steroid use. ${ }^{8,49}$ Furthermore, patients with a diagnosis of ulcerative colitis/Crohn's disease and bowel obstruction or perforation have a greater risk of deep/organ space infection. ${ }^{49}$ Similarly, a separate study of adults undergoing abdominal colorectal surgery also demonstrated an association of higher BMI with superficial SSI whereas preoperative radiation, postoperative hyperglycemia, and case length were associated with organ space infections. ${ }^{9}$ Race and ethnicity has not been associated with any SSI outcome in these systems. ${ }^{8}$

\section{Identification}

Early identification of SSIs begins with careful history and physical examination. The majority of these, excluding SSIs involving implants, are diagnosed after discharge, but within 3 weeks from the operation. ${ }^{64}$ For superficial SSIs, margins of the site should be marked in order to more readily observe signs of progression (Figure 1). ${ }^{10}$ When presenting with systemic signs of infection, wound/tissue and blood samples for gram stain, culture, and susceptibility should be obtained and will help guide therapy. ${ }^{2}$ Furthermore, any drainage should be

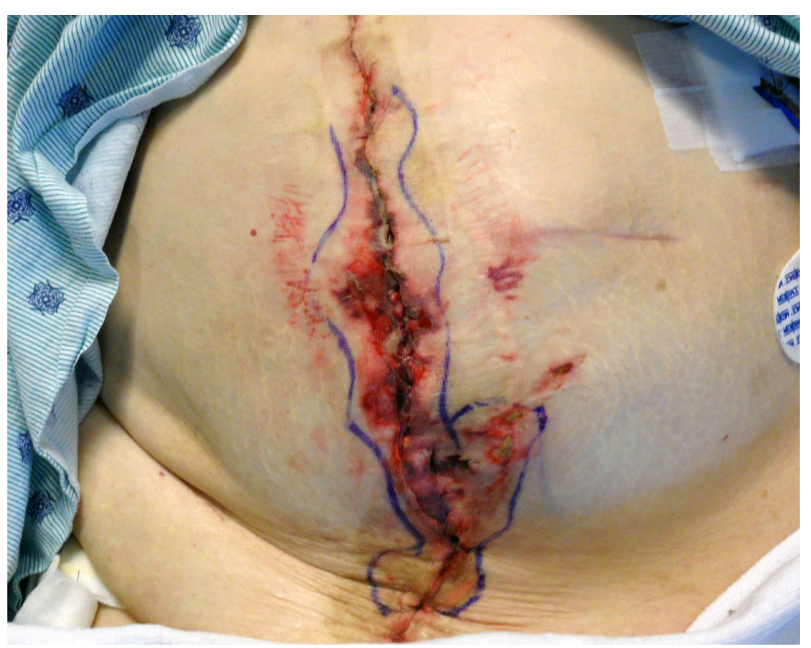

Figure I Example of a superficial site infection with necrotic margins. sampled and sent off for gram stain and culture. Laboratory testing that may be necessary depending on the clinical presentation of the patient includes complete blood cell count with differential, C-reactive protein, creatine phosphokinase, and basic metabolic panel to assess for creatinine/renal insufficiency and any metabolic/electrolyte abnormalities. ${ }^{2,6,10}$ These values may help in the diagnosis, but none are specific for SSI. Additionally, it is important to note that SSIs may present without laboratory abnormalities. When working up deep and organ space SSIs, computed tomography is particularly useful and more reliable in detecting free air in soft tissues than plain abdominal radiograph. Furthermore, computed tomography imaging helps guide procedural intervention (eg, interventional radiology percutaneous drainage). ${ }^{6}$

\section{Superficial/incisional}

Superficial SSI (Table 3) is defined as an infection involving only the skin or subcutaneous tissue occurring within 30 days of an operation (Figure 1). ${ }^{1}$ Additionally, at least one of the following must be present: 1) diagnosis by the surgeon or attending physician; 2) purulent drainage with or without laboratory confirmation from the surgical site; 3 ) aseptically obtained culture (tissue or fluid) demonstrating causative organisms; 4) presence of symptoms such as pain/tenderness, redness, localized swelling, or heat and the site opened by the surgeon if the culture is positive. ${ }^{1}$

\section{Deep tissue}

Deep incisional SSIs involve the deep soft tissues (Table 3) including the fascia and muscle layers of the incision and occurs within 30 days after the operation or within 1 year if an implant is in place and the infection appears to be associated with the surgery. ${ }^{1}$ Additionally, one of the following must be present: 1) diagnosis by an attending physician or surgeon; 2) purulent drainage from the deep tissue site but not from a deeper source (organ space); 3 ) the deep incision is either

Table 3 Surgical site infection categories and management

\begin{tabular}{|c|c|c|}
\hline Type of wound & Definition' & Management \\
\hline $\begin{array}{l}\text { Superficial } \\
\text { incisional }\end{array}$ & $\begin{array}{l}\text { Involves skin or } \\
\text { subcutaneous tissue of } \\
\text { the incision and rarely } \\
\text { leads to systemic toxicity }\end{array}$ & $\begin{array}{l}\text { Oral antibiotics in the } \\
\text { case of uncomplicated } \\
\text { superficial (eg, cellulitis); } \\
\text { incision and drainage for } \\
\text { complicated infections }\end{array}$ \\
\hline Deep incisional & $\begin{array}{l}\text { Includes tissues down to } \\
\text { and including fascia and } \\
\text { muscle }\end{array}$ & $\begin{array}{l}\text { Anatomic source } \\
\text { control plus appropriate } \\
\text { antibiotics }\end{array}$ \\
\hline Organ space & $\begin{array}{l}\text { Involves any body cavity } \\
\text { that was opened or } \\
\text { manipulated during surgery }\end{array}$ & $\begin{array}{l}\text { Anatomic source } \\
\text { control plus appropriate } \\
\text { antibiotics }\end{array}$ \\
\hline
\end{tabular}


opened by the surgeon in the setting of signs and symptoms of infection (eg, fever $>38^{\circ} \mathrm{C}$, tenderness, pain) or dehisces spontaneously; 4) evidence of infection (eg, abscess) is identified during the work-up, management, or by histopathologic or radiologic examination. ${ }^{1}$

\section{Organ space}

Organ space SSI (Table 3) involves the abdominal cavity that was manipulated during the surgery and occurs within 30 days after the operation or within 1 year if an implant is left in place. Furthermore, the infection appears to be related to the surgery but does not involve the superficial incision. One of the following must also be present: 1) diagnosis by an attending or surgeon; 2) evidence of infection (eg, abscess) is identified during the work-up, management, or by histopathologic or radiologic examination; 3) aseptically obtained culture (tissue or fluid) demonstrating causative organisms; 4) purulent drainage from the cavity, as from a percutaneously placed drain or during reoperation. ${ }^{1}$

\section{Management}

In order to effectively treat a SSI, antibiotics and anatomical source control may be necessary. ${ }^{2,10,65-67}$ Source control is achieved through surgical (eg, operative debridement) or procedural (eg, interventional percutaneous drainage) intervention. Inpatient hospital admission should be sought when the infection and resultant clinical sequelae are concerning. Supportive care and resuscitation is necessary for patients with hemodynamic changes and/or systemic inflammatory response syndrome.

Uncomplicated superficial SSIs, such as cellulitis, may be effectively managed with oral antibiotics without surgical intervention and debridement (Table 3$){ }^{6}$ Antimicrobial therapy is recommended for 5 days and extended if clinical signs of infection persist or worsen. ${ }^{10}$ If physical exam (eg, purulent drainage) and imaging suggests a deeper infection (ie, deep or organ space), then suture removal, incision and drainage, and debridement of necrotic tissue should be performed. ${ }^{6,10}$ Furthermore, deep and organ space SSIs require surgical debridement and operative or interventional drainage of the infected fluid collection. ${ }^{6,49,68}$ Empiric systemic antibiotics should be started as soon as a deep or organ space SSI is suspected and when clinical signs of infection are present (ie, fever $>38.5^{\circ} \mathrm{C}$, abnormal vital signs, erythema and induration extending $>5 \mathrm{~cm}$ from the wound edge, white blood cell count $>12,000 / \mu \mathrm{L}) .{ }^{10}$ Type and duration of empiric antimicrobial therapy is based upon expected pathogens which is determined by clinical presentation, anatomic site, comorbidities, and physical exam. ${ }^{69}$ The antibiotics are then tailored to culture results as soon as that data become available. ${ }^{1}$

As mentioned previously, the most commonly implicated pathogens in superficial SSIs include gram-positive bacteria, mainly S. aureus, and coagulase-negative staphylococci. ${ }^{50,69-74}$ Antimicrobial therapy should target these organisms as well as methicillin-resistant $S$. aureus (MRSA) in patients with specific risk factors (eg, presence of non-penetrating trauma, positive MRSA nasal swab or MRSA infection elsewhere, and history of intravenous drug abuse). ${ }^{73}$ First line empiric therapy consists of a first-generation cephalosporin (eg, cefazolin) or an anti-staphylococcal penicillin (for methicillinsensitive $S$. aureus). ${ }^{69}$ Vancomycin, daptomycin, linezolid, or an equivalent antibiotic are appropriate when targeting MRSA. ${ }^{69}$ In penicillin-allergic patients, clindamycin rather than a macrolide is the recommended antimicrobial agent. Gram-negatives and mixed organisms, such as Pseudomonas aeruginosa, Enterococcus spp., Escherichia coli, and other Enterobacteriaceae are often present in wound infections that follow gastrointestinal/genitourinary surgery. Therefore, broad-spectrum antimicrobial coverage active against gramnegatives and anaerobes should be used in these cases. ${ }^{10}$ Examples include vancomycin plus piperacillin/tazobactam or imipenem/meropenem, and cephalosporin or fluoroquinolone in combination with metronidazole. ${ }^{10} \mathrm{~A}$ recent prospective evaluation of antimicrobial therapy duration for intra-abdominal infection in patients who had undergone adequate source-control procedures demonstrated similar outcomes in fixed-duration antibiotic therapy (4 days) when compared to patients treated with a longer time duration (8 days) that extended beyond resolution of symptoms. ${ }^{66}$

Necrotizing fasciitis is a more severe infection that is often grouped among SSIs and requires immediate surgical consultation and intervention. ${ }^{10}$ Dish-water pus from a wound postoperatively has been described as one of the clinical presentations, along with leukocytosis $>15,000 / \mathrm{mm}^{3}$ in the setting of hyponatremia (sodium $<135 \mathrm{meq} / \mathrm{L}$ ). ${ }^{75}$ Necrotizing fasciitis is often polymicrobial and, therefore, broad-spectrum empiric antibiotic treatment should be initiated. Examples of proper antibiotic coverage include vancomycin or linezolid plus piperacillin/tazobactam, or a carbapenem. For documented group A streptococcal necrotizing fasciitis, penicillin plus clindamycin is an appropriate treatment regimen. ${ }^{10}$

\section{Prevention}

It is estimated that approximately half of SSIs are preventable. ${ }^{76-80}$ Common practices that have been shown to reduce 
the incidence of SSIs include administering prophylactic antibiotics prior to incision, clipping rather than shaving the operative site, maintaining normal body temperature and oxygen supplementation perioperatively, and achieving adequate glycemic control (Table 4). ${ }^{60,81-90}$ Simply introducing a surgical safety checklist has even been shown to reduce morbidity and mortality in noncardiac surgery patients. ${ }^{91}$ Advances in surgical approach, including laparoscopy, intraoperative wound irrigation, the use of wound protectors during an operation, and negative pressure wound therapy (NPWT) systems afterward have also been shown to reduce wound morbidity at follow-up..$^{22,92-95}$

NPWT (Figure 2) is a technique often employed at the abdominal incision/wound following a general surgery operation that incorporates a foam dressing and suction pump that provides an airtight seal to the wound. NPWT has also been used for the management of ulcers, skin flaps, grafts, and burns. Following placement, an adjustable negative pressure is applied to the dressing, which helps to provide a sterile airtight seal to the wound in the initial postoperative period until the initial dressing change by the surgical team. The technique used most often at our institution has been previously described and shown to reduce wound morbidity postoperatively when compared to standard dressings. ${ }^{92}$
This observation was also reported in other series, with a decrease in the incidence of SSI and other occurrences (eg, seroma) following abdominal surgery. ${ }^{96,97}$ Furthermore, a reduction in overall mortality and improvement in primary fascial closure rates has been observed with the use of variations of NPWT in patients requiring open abdomen following trauma or general surgery. ${ }^{98}$ Methods by which the vacuumassisted closure (VAC) therapy is thought to lessen wound morbidity include increased microvascular blood flow to the wound margins and tissue bed as well as enhanced removal of excessive edema while maintaining adequate wound moisture for healing. ${ }^{92,99}$ Furthermore, significantly decreased bacterial counts and increased rates of granulation tissue have been observed in animal models using NPWT. ${ }^{96}$

Other approaches that have been used in the past in an attempt to reduce the incidence of postoperative SSIs include covering surgical wounds with sterile dressings for up to 48 hours postoperatively. However, there is insufficient evidence to show that such a practice reduces SSI rate at this point. ${ }^{50,100,101}$ Additionally, there has been much interest in the use of antibiotic coated sutures for abdominal wall closure for the reduction of SSIs. Despite prior meta-analyses, the recent PROUD trial demonstrated no benefit in triclosancoated polydioxanone (PDS) closure compared to control/

Table 4 Recommendations for the prevention of postoperative abdominal wound infections

\section{Preoperative prevention \\ Checklists \\ Smoking cessation \\ Blood glucose control \\ Skin preparation}

Hair removal

Antimicrobial prophylaxis

\section{Intraoperative prevention Maintenance of normothermia Maximize tissue oxygenation \\ Wound protectors \\ Postoperative prevention \\ Blood glucose control \\ Wound dressings}

Use a World Health Organization-based checklist to increase compliance with best practices ${ }^{115}$ Encourage smoking cessation for at least 30 days prior to procedure ${ }^{50}$

Attempt to control blood glucose levels in diabetic patients and avoid hyperglycemia perioperatively ${ }^{50,81}$ Clear skin of gross contamination ${ }^{50}$

Perform prep in concentric circles, beginning with area of incision ${ }^{50}$

Use alcohol-containing antisepsis agents unless contraindicated, combined with chlorhexidine gluconate or an iodophor (eg, povidone-iodine) $)^{50}$

Do not remove hair unless necessary $y^{50,60,104,115}$

When hair is to be removed, use electric clippers with a single-use head; do not use razors ${ }^{50,60,81}$

Administer antimicrobial prophylaxis only when indicated, and according to evidence-based guidelines ${ }^{105-114}$

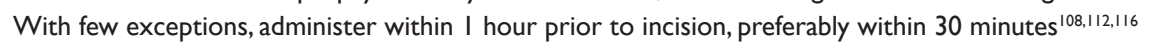
Discontinue within 24 hours after surgery (up to 72 hours for cardiothoracic procedures in adults) ) $^{50,104,112}$ Adjust dosing for patient weight and redose for longer cases or in cases of excessive blood loss $s^{50,107,115}$ Use a combination of parenteral and oral antimicrobials with mechanical bowel preparations prior to colorectal procedures $50,103,112,114$

Maintain perioperative normothermia ( $\geq 35.5$ degrees) ${ }^{85}$

Administer supplemental oxygen during and after surgical procedures with general anesthesia and mechanical ventilation ${ }^{90,115}$

Use wound protectors for open abdominal surgery ${ }^{23}$

Maintain immediate postoperative glucose at $180 \mathrm{mg} / \mathrm{dL}$ or lower, particularly for cardiac surgery patients $50,81,104$

Protect primarily closed wounds with sterile dressings for $24-48$ hours postoperatively ${ }^{50,100,101}$

Note: These recommendations are based largely from expert opinion, retrospective case series, systematic/meta-analysis reviews, and prospective studies, and further studies are necessary to further explore and validate these recommendations. 


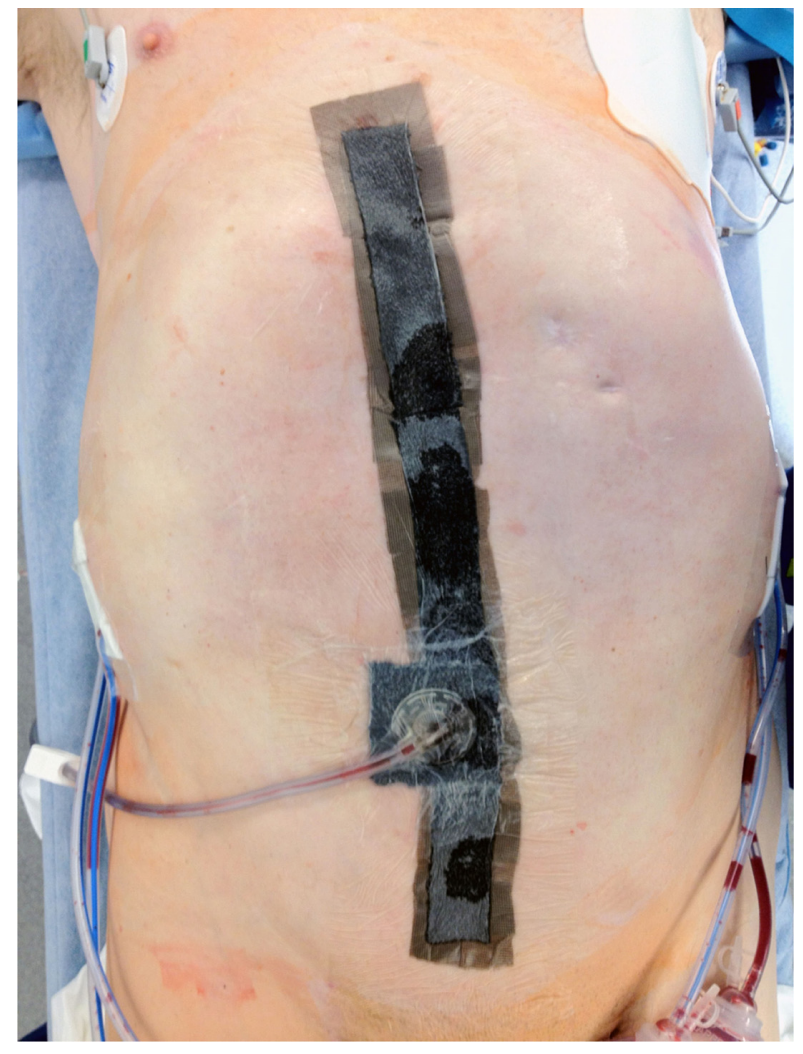

Figure 2 Examples of negative pressure wound therapy system previously shown to reduce the risk of surgical site infection.

uncoated closure. ${ }^{21,102,103}$ Finally, closed suction drainage, whether placed in a subcutaneous or intra-abdominal location, should be used judiciously as regular use may be associated with an increased risk of infection. ${ }^{40,68}$

Prophylactic antibiotic timing is a nationally mandated quality metric and the timing of administration of preincision antibiotics has been well studied. ${ }^{104-108}$ The utility of prophylactic antibiotics in clean cases remains controversial. ${ }^{100}$ Prophylaxis is most appropriate in any case where contamination is evident or expected. Historic data suggests that the efficacy of prophylactic antibiotics is reduced when they are administered too early prior to incision or after the start of the operation. ${ }^{109-111}$ Antibiotic prophylaxis should be administered $<1$ hour prior to incision; evidence in support of this measure is primarily based off of a large multicenter prospective study. ${ }^{108,112}$ The type of antibiotic administered does appear to affect SSI following gastrointestinal surgery and ensuring the appropriate selection of coverage is crucial. For instance, SSI outcomes following colorectal surgery are improved when using cefazolin/metronidazole, ciprofloxacin/metronidazole, and ertapenem. ${ }^{82,107,108,113}$ Furthermore, the use of parenteral and oral antimicrobials with mechanical bowel preparations has been shown to reduce SSIs following colorectal surgery. ${ }^{114}$ Prophylactic antibiotics duration should not exceed 24 hours after surgery. ${ }^{50,104,112,115,116}$ Furthermore, redosing of antibiotics is important, particularly during long cases, and is based on blood loss and antibiotic half-life. ${ }^{107}$

The impact of skin decontamination on reducing the rate of SSIs has been well studied. ${ }^{117-120}$ Investigators have evaluated the use of nasal mupirocin/chlorhexidine as part of a decolonization program for MRSA in an attempt to prevent spread and ultimately reduce SSIs. ${ }^{121}$ Results on its use have been inconsistent and such a practice has been criticized by many, given the potential for increased resistance in these offending bacteria and concern over the cost-effectiveness of this approach. ${ }^{120,121}$ More persuasive evidence supports the use of alcohol-based chlorhexidine products compared to povidone-iodine, with the potential for reduced postoperative SSI even for clean cases. ${ }^{100,119,122,123}$

Collaborative initiatives to reduce the incidence of SSIs are expanding. The CDC established the National Nosocomial Infections Surveillance system in the 1970s as a way to monitor infection rates at acute care hospitals in the USA. Today, this system is known as the National Healthcare Safety Network (NHSN) ${ }^{80}$ Other similar programs include the ACS-NSQIP and the Veterans Affairs Surgical Quality Improvement Program. ${ }^{80}$ The CDC and Centers for Medicare and Medicaid Services implemented the National Surgical Infection Prevention Project in 2002, with the aim to decrease morbidity and mortality associated with postoperative SSI. ${ }^{104,124}$ Performance measures for national surveillance and quality improvement for antimicrobial prophylaxis included proportion of patients who are given prophylactic antibiotics consistent with published guidelines, within 1 hour prior to incision (within 2 hours for vancomycin or fluoroquinolones), and whose prophylactic regimen is discontinued within 24 hours after surgery. ${ }^{104,124}$ In adherence to these three measures, 56 hospitals were able to reduce their SSI rate by $27 \%$ (from $2.3 \%$ to $1.7 \%$ ) over a 3 month period. ${ }^{125}$ Similarly, the Surgical Care Improvement Project (SCIP) is a national quality partnership of organizations committed to improving safety of surgical care through the prevention of SSIs, as well as other complications (ie, venous thromboembolism, adverse cardiac events, etc). ${ }^{104}$ Despite a high compliance rate with SCIP measures, there has not been a significant reduction in the observed SSI rate. ${ }^{126} \mathrm{~A}$ recent study by Wick et al highlights that the implementation of a surgery-based comprehensive unit-based safety program is a safe and effective way to improve the quality of care for patients through the implementation of evidence-based 
standardized interventions. ${ }^{127}$ After demonstrating a nearly one-third reduction of colorectal SSI rate at the Johns Hopkins Hospital, Baltimore, MD, USA, such an approach is now being employed at many other health care facilities around the USA.

\section{Conclusion}

SSIs complicate the recovery course of a significant proportion of general abdominal surgical patients and are associated with excessive health care costs. SSIs increase postoperative morbidity and mortality, and may require hospital admission, intravenous antibiotics, and even surgical reintervention. Risks associated with SSIs are both related to host and perioperative factors. However, many of these are modifiable and a concerted effort by the patient and physician surgeon to make changes can improve outcomes. As it has been shown that a vast majority of these infections are preventable, quality initiative programs such as ACS-NSQIP are expanding their roles to help better monitor adherence to improvement measures. Indeed, standardizing preoperative antibiotic prophylaxis timing is perhaps the most persuasive example and this has been integral to reducing postoperative SSI rate. Additional studies are necessary to further evaluate other areas that can be improved upon to reduce SSI rate and ultimately improve the delivery of care to surgical patients.

\section{Disclosure}

The authors report no conflicts of interest in this work.

\section{References}

1. Horan TC, Gaynes RP, Martone WJ, Jarvis WR, Emori TG. CDC definitions of nosocomial surgical site infections, 1992: a modification of CDC definitions of surgical wound infections. Infect Control Hosp Epidemiol. 1992;13(10):606-608.

2. Barie PS, Wilson SE. Impact of evolving epidemiology on treatments for complicated skin and skin structure infections: the surgical perspective. J Am Coll Surg. 2015;220(1):105-106.

3. Horan TC, Andrus M, Dudeck MA. CDC/NHSN surveillance definition of health care-associated infection and criteria for specific types of infections in the acute care setting. Am J Infect Control. 2008;36(5): 309-332.

4. Altemeier WA, Culbertson WR, Hummel RP. Surgical considerations of endogenous infections - sources, types, and methods of control. Surg Clin North Am. 1968;48(1):227-240.

5. Cheadle WG. Risk factors for surgical site infection. Surg Infect (Larchmt). 2006;7 Suppl 1:S7-S11.

6. Anderson DJ. Surgical site infections. Infect Dis Clin North Am. 2011; 25(1):135-153.

7. Anderson DJ, Chen LF, Sexton DJ, Kaye KS. Complex surgical site infections and the devilish details of risk adjustment: important implications for public reporting. Infect Control Hosp Epidemiol. 2008; 29(10):941-946.

8. Segal CG, Waller DK, Tilley B, Piller L, Bilimoria K. An evaluation of differences in risk factors for individual types of surgical site infections after colon surgery. Surgery. 2014;156(5):1253-1260.
9. Ho VP, Stein SL, Trencheva K, et al. Differing risk factors for incisional and organ/space surgical site infections following abdominal colorectal surgery. Dis Colon Rectum. 2011;54(7):818-825.

10. Stevens DL, Bisno AL, Chambers HF, et al. Practice guidelines for the diagnosis and management of skin and soft tissue infections: 2014 update by the Infectious Diseases Society of America. Clin Infect Dis. 2014;59(2):e10-e52.

11. Khuri SF, Henderson WG, DePalma RG, et al. Determinants of long-term survival after major surgery and the adverse effect of postoperative complications. Ann Surg. 2005;242(3):326-341; discussion 341-343.

12. Drapeau CM, Pan A, Bellacosa C, et al. Surgical site infections in HIV-infected patients: results from an Italian prospective multicenter observational study. Infection. 2009;37(5):455-460.

13. Neumayer L, Hosokawa P, Itani K, El-Tamer M, Henderson WG, Khuri SF. Multivariable predictors of postoperative surgical site infection after general and vascular surgery: results from the patient safety in surgery study. $J$ Am Coll Surg. 2007;204(6):1178-1187.

14. Hechenbleikner EM, Hobson DB, Bennett JL, Wick EC. Implementation of surgical quality improvement: auditing tool for surgical site infection prevention practices. Dis Colon Rectum. 2015;58(1):83-90.

15. Young PY, Khadaroo RG. Surgical site infections. Surg Clin North Am. 2014;94(6):1245-1264.

16. Alexander JW, Solomkin JS, Edwards MJ. Updated recommendations for control of surgical site infections. Ann Surg. 2011;253(6):1082-1093.

17. Klevens RM, Edwards JR, Richards CL Jr, et al. Estimating health care-associated infections and deaths in US hospitals, 2002. Public Health Rep. 2007;122(2):160-166.

18. de Lissovoy G, Fraeman K, Hutchins V, Murphy D, Song D, Vaughn BB. Surgical site infection: incidence and impact on hospital utilization and treatment costs. Am J Infect Control. 2009;37(5):387-397.

19. Fry DE. The economic costs of surgical site infection. Surg Infect (Larchmt). 2002;3 Suppl 1:S37-S43.

20. Anderson DJ, Hartwig MG, Pappas T, et al. Surgical volume and the risk of surgical site infection in community hospitals: size matters. Ann Surg. 2008;247(2):343-349.

21. Diener MK, Knebel P, Kieser M, Schuler P, Schiergens TS, Atanassov V, et al. Effectiveness of triclosan-coated PDS Plus versus uncoated PDS II sutures for prevention of surgical site infection after abdominal wall closure: the randomised controlled PROUD trial. Lancet. 2014;384(9938):142-152.

22. Pinkney TD, Calvert M, Bartlett DC, et al. Impact of wound edge protection devices on surgical site infection after laparotomy: multicentre randomised controlled trial (ROSSINI Trial). BMJ. 2013;347:f4305.

23. Mihaljevic AL, Schirren R, Özer M, et al. Multicenter double-blinded randomized controlled trial of standard abdominal wound edge protection with surgical dressings versus coverage with a sterile circular polyethylene drape for prevention of surgical site infections: a CHIRNet trial (BaFO; NCT01181206). Ann Surg. 2014;260(5):730-737; discussion 737-739.

24. Blumetti J, Luu M, Sarosi G, et al. Surgical site infections after colorectal surgery: do risk factors vary depending on the type of infection considered? Surgery. 2007;142(5):704-711.

25. Merkow RP, Ju MH, Chung JW, et al. Underlying reasons associated with hospital readmission following surgery in the United States. JAMA. 2015;313(5):483-495

26. Magill SS, Edwards JR, Bamberg W, et al. Multistate point-prevalence survey of health care-associated infections. $N$ Engl J Med. 2014; 370(13):1198-1208.

27. Cohen B, Choi YJ, Hyman S, Furuya EY, Neidell M, Larson E. Gender differences in risk of bloodstream and surgical site infections. J Gen Intern Med. 2013;28(10):1318-1325.

28. Kaye KS, Schmader KE, Sawyer R. Surgical site infection in the elderly population. Clin Infect Dis. 2004;39(12):1835-1841.

29. Boltz MM, Hollenbeak CS, Julian KG, Ortenzi G, Dillon PW. Hospital costs associated with surgical site infections in general and vascular surgery patients. Surgery. 2011;150(5):934-942. 
30. Kaye KS, Schmit K, Pieper C, et al. The effect of increasing age on the risk of surgical site infection. J Infect Dis. 2005;191(7): 1056-1062.

31. Itani KM, Merchant S, Lin SJ, Akhras K, Alandete JC, Hatoum HT. Outcomes and management costs in patients hospitalized for skin and skin-structure infections. Am J Infect Control. 2011;39(1):42-49.

32. Schweizer ML, Cullen JJ, Perencevich EN, Vaughan Sarrazin MS. Costs Associated With Surgical Site Infections in Veterans Affairs Hospitals. JAMA Surg. Epub 2014 May 21.

33. Zimlichman E, Henderson D, Tamir O, et al. Health care-associated infections: a meta-analysis of costs and financial impact on the US health care system. JAMA Intern Med. 2013;173(22):2039-2046.

34. Pallin DJ, Egan DJ, Pelletier AJ, Espinola JA, Hooper DC, Camargo CA Jr. Increased US emergency department visits for skin and soft tissue infections, and changes in antibiotic choices, during the emergence of community-associated methicillin-resistant Staphylococcus aureus. Ann Emerg Med. 2008;51(3):291-298.

35. Edelsberg J, Taneja C, Zervos M, et al. Trends in US hospital admissions for skin and soft tissue infections. Emerg Infect Dis. 2009;15(9): $1516-1518$

36. Anderson DJ, Pyatt DG, Weber DJ, Rutala WA; North Carolina Department of Public Health HAI Advisory Group. Statewide costs of health care-associated infections: estimates for acute care hospitals in North Carolina. Am J Infect Control. 2013;41(9):764-768.

37. National Collaborating Centre for Women's and Children's Health (UK). Surgical Site Infection: Prevention and Treatment of Surgical Site Infection. London: RCOG Press; 2008.

38. Haridas M, Malangoni MA. Predictive factors for surgical site infection in general surgery. Surgery. 2008;144(4):496-501; discussion 501-503.

39. Angeles-Garay U, Morales-Márquez LI, Sandoval-Balanzarios MA, Velázquez-García JA, Maldonado-Torres L, Méndez-Cano AF. [Risk factors related to surgical site infection in elective surgery]. Cir Cir. 2014;82(1):48-62. Spanish.

40. Isik O, Kaya E, Sarkut P, Dundar HZ. Factors Affecting Surgical Site Infection Rates in Hepatobiliary Surgery. Surg Infect (Larchmt). 2015; 16(3):281-286.

41. Gaynes RP, Culver DH, Horan TC, Edwards JR, Richards C, Tolson JS. Surgical site infection (SSI) rates in the United States, 1992-1998: the National Nosocomial Infections Surveillance System basic SSI risk index. Clin Infect Dis. 2001;33 Suppl 2:S69-S77.

42. Pessaux P, Msika S, Atalla D, Hay JM, Flamant Y; French Association for Surgical Research. Risk factors for postoperative infectious complications in noncolorectal abdominal surgery: a multivariate analysis based on a prospective multicenter study of 4718 patients. Arch Surg. 2003;138(3):314-324.

43. de Oliveira AC, Ciosak SI, Ferraz EM, Grinbaum RS. Surgical site infection in patients submitted to digestive surgery: risk prediction and the NNIS risk index. Am J Infect Control. 2006;34(4):201-207.

44. Culver DH, Horan TC, Gaynes RP, et al. Surgical wound infection rates by wound class, operative procedure, and patient risk index. National Nosocomial Infections Surveillance System. Am J Med. 1991;91(3B): $152 \mathrm{~S}-157 \mathrm{~S}$

45. Sørensen LT, Hemmingsen U, Kallehave F, et al. Risk factors for tissue and wound complications in gastrointestinal surgery. Ann Surg. 2005; 241(4):654-658

46. Offner PJ, Moore EE, Biffl WL. Male gender is a risk factor for major infections after surgery. Arch Surg. 1999;134(9):935-938; discussion 938-940.

47. Lenhardt R, Hopf HW, Marker E, et al. Perioperative collagen deposition in elderly and young men and women. Arch Surg. 2000;135(1): 71-74.

48. Cruse PJ, Foord R. A five-year prospective study of 23,649 surgical wounds. Arch Surg. 1973;107(2):206-210.

49. Lawson EH, Hall BL, Ko CY. Risk factors for superficial vs deep/ organ-space surgical site infections: implications for quality improvement initiatives. JAMA Surg. 2013;148(9):849-858.
50. Mangram AJ, Horan TC, Pearson ML, Silver LC, Jarvis WR. Guideline for prevention of surgical site infection, 1999. Hospital Infection Control Practices Advisory Committee. Infect Control Hosp Epidemiol. 1999;20(4):250-278; quiz 279-280.

51. Krizek TJ, Robson MC. Evolution of quantitative bacteriology in wound management. Am J Surg. 1975;130(5):579-584.

52. Houang ET, Ahmet Z. Intraoperative wound contamination during abdominal hysterectomy. $J$ Hosp Infect. 1991;19(3):181-189.

53. Edwards R, Harding KG. Bacteria and wound healing. Curr Opin Infect Dis. 2004;17(2):91-96.

54. Bowler PG, Duerden BI, Armstrong DG. Wound microbiology and associated approaches to wound management. Clin Microbiol Rev. 2001;14(2):244-269.

55. Kallstrom G. Are quantitative bacterial wound cultures useful? J Clin Microbiol. 2014;52(8):2753-2756.

56. Zhang L, Liu BC, Zhang XY, Li L, Xia XJ, Guo RZ. Prevention and treatment of surgical site infection in HIV-infected patients. BMC Infect Dis. 2012;12:115.

57. Emparan C, Iturburu IM, Ortiz J, Mendez JJ. Infective complications after abdominal surgery in patients infected with human immunodeficiency virus: role of CD4+ lymphocytes in prognosis. World J Surg. 1998;22(8):778-782.

58. Jensen JA, Goodson WH, Hopf HW, Hunt TK. Cigarette smoking decreases tissue oxygen. Arch Surg. 1991;126(9):1131-1134.

59. Hopf HW, Hunt TK, West JM, et al. Wound tissue oxygen tension predicts the risk of wound infection in surgical patients. Arch Surg. 1997;132(9):997-1004; discussion 1005.

60. Tanner J, Norrie P, Melen K. Preoperative hair removal to reduce surgical site infection. Cochrane Database Syst Rev. 2011;(11): CD004122.

61. Leong G, Wilson J, Charlett A. Duration of operation as a risk factor for surgical site infection: comparison of English and US data. $J$ Hosp Infect. 2006;63(3):255-262.

62. Weber WP, Zwahlen M, Reck S, et al. The association of preoperative anemia and perioperative allogeneic blood transfusion with the risk of surgical site infection. Transfusion. 2009;49(9): 1964-1970.

63. Watanabe A, Kohnoe S, Shimabukuro R, et al. Risk factors associated with surgical site infection in upper and lower gastrointestinal surgery. Surg Today. 2008;38(5):404-412.

64. Sands K, Vineyard G, Platt R. Surgical site infections occurring after hospital discharge. J Infect Dis. 1996;173(4):963-970.

65. Eron LJ, Lipsky BA, Low DE, et al. Managing skin and soft tissue infections: expert panel recommendations on key decision points. J Antimicrob Chemother. 2003;52 Suppl 1:i3-i17.

66. Sawyer RG, Claridge JA, Nathens AB, et al. Trial of short-course antimicrobial therapy for intraabdominal infection. $N$ Engl $J$ Med. 2015;372(21):1996-2005

67. May AK, Stafford RE, Bulger EM, et al. Treatment of complicated skin and soft tissue infections. Surg Infect (Larchmt). 2009;10(5): 467-499.

68. Schein M. To drain or not to drain? The role of drainage in the contaminated and infected abdomen: an international and personal perspective. World J Surg. 2008;32(2):312-321.

69. Fung HB, Chang JY, Kuczynski S. A practical guide to the treatment of complicated skin and soft tissue infections. Drugs. 2003;63(14): $1459-1480$

70. Lee SY, Kuti JL, Nicolau DP. Antimicrobial management of complicated skin and skin structure infections in the era of emerging resistance. Surg Infect (Larchmt). 2005;6(3):283-295.

71. Jernigan JA. Is the burden of Staphylococcus aureus among patients with surgical-site infections growing? Infect Control Hosp Epidemiol. 2004;25(6):457-460.

72. Jernigan JA, Pullen AL, Partin C, Jarvis WR. Prevalence of and risk factors for colonization with methicillin-resistant Staphylococcus aureus in an outpatient clinic population. Infect Control Hosp Epidemiol. 2003; 24(6):445-450. 
73. Jernigan JA, Pullen AL, Flowers L, Bell M, Jarvis WR. Prevalence of and risk factors for colonization with methicillin-resistant Staphylococcus aureus at the time of hospital admission. Infect Control Hosp Epidemiol. 2003;24(6):409-414.

74. Kalra L, Camacho F, Whitener CJ, et al. Risk of methicillin-resistant Staphylococcus aureus surgical site infection in patients with nasal MRSA colonization. Am J Infect Control. 2013;41(12):1253-1257.

75. Wall DB, Klein SR, Black S, de Virgilio C. A simple model to help distinguish necrotizing fasciitis from nonnecrotizing soft tissue infection. J Am Coll Surg. 2000;191(3):227-231.

76. Odom-Forren J. Preventing surgical site infections. Nursing. 2006;36(6): 58-63; quiz 63-64.

77. Shaffer VO, Baptiste CD, Liu Y, et al. Improving quality of surgical care and outcomes: factors impacting surgical site infection after colorectal resection. Am Surg. 2014;80(8):759-763.

78. Kirby JP, Mazuski JE. Prevention of surgical site infection. Surg Clin North Am. 2009;89(2):365-389, viii.

79. Polk HC Jr, Lopez-Mayor JF. Postoperative wound infection: a prospective study of determinant factors and prevention. Surgery. 1969;66(1):97-103.

80. Najjar PA, Smink DS. Prophylactic antibiotics and prevention of surgical site infections. Surg Clin North Am. 2015;95(2):269-283.

81. Dronge AS, Perkal MF, Kancir S, Concato J, Aslan M, Rosenthal RA. Long-term glycemic control and postoperative infectious complications Arch Surg. 2006;141(4):375-380; discussion 380.

82. Hendren S, Fritze D, Banerjee M, et al. Antibiotic choice is independently associated with risk of surgical site infection after colectomy: a population-based cohort study. Ann Surg. 2013;257(3):469-475.

83. Melton GB, Vogel JD, Swenson BR, Remzi FH, Rothenberger DA, Wick EC. Continuous intraoperative temperature measurement and surgical site infection risk: analysis of anesthesia information system data in 1008 colorectal procedures. Ann Surg. 2013;258(4):606-612; discussion 612-613.

84. Baucom RB, Phillips SE, Ehrenfeld JM, et al. Association of Perioperative Hypothermia During Colectomy With Surgical Site Infection. JAMA Surg. 2015;150(6):570-575.

85. Wong PF, Kumar S, Bohra A, Whetter D, Leaper DJ. Randomized clinical trial of perioperative systemic warming in major elective abdominal surgery. Br J Surg. 2007;94(4):421-426.

86. Jacober SJ, Sowers JR. An update on perioperative management of diabetes. Arch Intern Med. 1999;159(20):2405-2411.

87. Tanner J, Moncaster K, Woodings D. Preoperative hair removal: a systematic review. J Perioper Pract. 2007;17(3):118-121, 124-132.

88. Kurz A, Sessler DI, Lenhardt R. Perioperative normothermia to reduce the incidence of surgical-wound infection and shorten hospitalization. Study of Wound Infection and Temperature Group. $N$ Engl J Med. 1996;334(19):1209-1215.

89. Melling AC, Ali B, Scott EM, Leaper DJ. Effects of preoperative warming on the incidence of wound infection after clean surgery: a randomised controlled trial. Lancet. 2001;358(9285):876-880.

90. Qadan M, Akça O, Mahid SS, Hornung CA, Polk HC Jr. Perioperative supplemental oxygen therapy and surgical site infection: a meta-analysis of randomized controlled trials. Arch Surg. 2009;144(4):359-366.

91. Haynes AB, Weiser TG, Berry WR, et al. A surgical safety checklist to reduce morbidity and mortality in a global population. $N$ Engl J Med. 2009;360(5):491-499.

92. Soares KC, Baltodano PA, Hicks CW, et al. Novel wound management system reduction of surgical site morbidity after ventral hernia repairs: a critical analysis. Am J Surg. 2015;209(2):324-332.

93. Mueller TC, Loos M, Haller B, et al. Intra-operative wound irrigation to reduce surgical site infections after abdominal surgery: a systematic review and meta-analysis. Langenbecks Arch Surg. 2015;400(2): $167-181$.

94. Gassman A, Mehta A, Bucholdz E, et al. Positive outcomes with negative pressure therapy over primarily closed large abdominal wall reconstruction reduces surgical site infection rates. Hernia. 2015;19(2): 273-278.
95. Gheorghe A, Calvert M, Pinkney TD, et al. Systematic review of the clinical effectiveness of wound-edge protection devices in reducing surgical site infection in patients undergoing open abdominal surgery. Ann Surg. 2012;255(6):1017-1029.

96. Condé-Green A, Chung TL, Holton LH 3rd, et al. Incisional negativepressure wound therapy versus conventional dressings following abdominal wall reconstruction: a comparative study. Ann Plast Surg 2013;71(4):394-397.

97. Blackham AU, Farrah JP, McCoy TP, Schmidt BS, Shen P. Prevention of surgical site infections in high-risk patients with laparotomy incisions using negative-pressure therapy. Am J Surg. 2013;205(6):647-654.

98. Cheatham ML, Demetriades D, Fabian TC, et al. Prospective study examining clinical outcomes associated with a negative pressure wound therapy system and Barker's vacuum packing technique. World J Surg. 2013;37(9):2018-2030.

99. Wackenfors A, Sjögren J, Gustafsson R, Algotsson L, Ingemansson R, Malmsjö M. Effects of vacuum-assisted closure therapy on inguinal wound edge microvascular blood flow. Wound Repair Regen. 2004; 12(6):600-606.

100. Leaper D, Ousey K. Evidence update on prevention of surgical site infection. Curr Opin Infect Dis. 2015;28(2):158-163.

101. Dumville JC, Gray TA, Walter CJ, Sharp CA, Page T. Dressings for the prevention of surgical site infection. Cochrane Database Syst Rev. 2014;9:CD003091

102. Wang ZX, Jiang CP, Cao Y, Ding YT. Systematic review and metaanalysis of triclosan-coated sutures for the prevention of surgical-site infection. Br J Surg. 2013;100(4):465-473.

103. Edmiston CE Jr, Daoud FC, Leaper D. Is there an evidence-based argument for embracing an antimicrobial (triclosan)-coated suture technology to reduce the risk for surgical-site infections? A metaanalysis. Surgery. 2014;155(2):362-363.

104. Bratzler DW, Hunt DR. The surgical infection prevention and surgical care improvement projects: national initiatives to improve outcomes for patients having surgery. Clin Infect Dis. 2006;43(3):322-330.

105. Miliani K, L'Heriteau F, Astagneau P; INCISO Network Study Group. Non-compliance with recommendations for the practice of antibiotic prophylaxis and risk of surgical site infection: results of a multilevel analysis from the INCISO Surveillance Network. J Antimicrob Chemother. 2009;64(6):1307-1315.

106. Classen DC, Evans RS, Pestotnik SL, Horn SD, Menlove RL, Burke JP. The timing of prophylactic administration of antibiotics and the risk of surgical-wound infection. N Engl J Med. 1992;326(5):281-286.

107. Hawn MT, Richman JS, Vick CC, et al. Timing of surgical antibiotic prophylaxis and the risk of surgical site infection. JAMA Surg. 2013; 148(7):649-657.

108. Testa M, Stillo M, Giacomelli S, et al. Appropriate use of antimicrobial prophylaxis: an observational study in 21 surgical wards. BMC Surg. 2015; $15: 63$.

109. Burke JF. The effective period of preventive antibiotic action in experimental incisions and dermal lesions. Surgery. 1961;50:161-168.

110. Stone HH, Hooper CA, Kolb LD, Geheber CE, Dawkins EJ. Antibiotic prophylaxis in gastric, biliary and colonic surgery. Ann Surg. 1976; 184(4):443-452.

111. Stone HH, Haney BB, Kolb LD, Geheber CE, Hooper CA. Prophylactic and preventive antibiotic therapy: timing, duration and economics. Ann Surg. 1979;189(6):691-699.

112. No authors listed. ASHP Therapeutic Guidelines on Antimicrobial Prophylaxis in Surgery. American Society of Health-System Pharmacists. Am J Health Syst Pharm. 1999;56(18):1839-1888.

113. Deierhoi RJ, Dawes LG, Vick C, Itani KM, Hawn MT. Choice of intravenous antibiotic prophylaxis for colorectal surgery does matter. J Am Coll Surg. 2013;217(5):763-769.

114. Nelson RL, Glenny AM, Song F. Antimicrobial prophylaxis for colorectal surgery. Cochrane Database Syst Rev. 2009;(1):CD001181.

115. Anderson DJ, Kaye KS, Classen D, et al. Strategies to prevent surgical site infections in acute care hospitals. Infect Control Hosp Epidemiol. 2008;29 Suppl 1:S51-S61. 
116. Steinberg JP, Braun BI, Hellinger WC, et al. Timing of antimicrobial prophylaxis and the risk of surgical site infections: results from the Trial to Reduce Antimicrobial Prophylaxis Errors. Ann Surg. 2009;250(1):10-16.

117. Webster J, Osborne S. Preoperative bathing or showering with skin antiseptics to prevent surgical site infection. Cochrane Database Syst Rev. 2015;2:CD004985.

118. Lynch W, Davey PG, Malek M, Byrne DJ, Napier A. Costeffectiveness analysis of the use of chlorhexidine detergent in preoperative whole-body disinfection in wound infection prophylaxis. J Hosp Infect. 1992;21(3):179-191.

119. Darouiche RO, Wall MJ Jr, Itani KM, et al. Chlorhexidine-Alcohol versus Povidone-Iodine for Surgical-Site Antisepsis. $N$ Engl J Med. 2010;362(1):18-26.

120. Hebert C, Robicsek A. Decolonization therapy in infection control. Curr Opin Infect Dis. 2010;23(4):340-345.

121. Anderson DJ. Prevention of surgical-site infections. $N$ Engl J Med. 2010;362(16):1540; authorreply 1542-1543
122. Dumville JC, McFarlane E, Edwards P, Lipp A, Holmes A, Liu Z. Preoperative skin antiseptics for preventing surgical wound infections after clean surgery. Cochrane Database Syst Rev. 2015;4:CD003949.

123. Echols K, Graves M, LeBlanc KG, Marzolf S, Yount A. Role of antiseptics in the prevention of surgical site infections. Dermatol Surg. 2015;41(6):667-676.

124. Bratzler DW, Houck PM; Surgical Infection Prevention Guideline Writers Workgroup. Antimicrobial prophylaxis for surgery: an advisory statement from the National Surgical Infection Prevention Project. Am J Surg. 2005;189(4):395-404.

125. Dellinger EP, Hausmann SM, Bratzler DW, et al. Hospitals collaborate to decrease surgical site infections. Am J Surg. 2005;190(1):9-15.

126. Hawn MT, Vick CC, Richman J, et al. Surgical site infection prevention: time to move beyond the surgical care improvement program. Ann Surg. 2011;254(3):494-499; discussion 499-501.

127. Wick EC, Hobson DB, Bennett JL, et al. Implementation of a surgical comprehensive unit-based safety program to reduce surgical site infections. J Am Coll Surg. 2012;215(2):193-200.

\section{Publish your work in this journal}

Chronic Wound Care Management and Research is an international, peer reviewed, open access, online journal publishing original research, reviews, editorials, and commentaries on the causes and management of chronic wounds and the major issues related to chronic wound management. Topics also include chronic wounds as comorbidities to other

\section{Dovepress}

conditions, patient adherence to therapy, and the economic burden of chronic wounds. The manuscript management system is completely online and includes a very quick and fair peer review system, which is all easy to use. Visit http://www.dovepress.com/testimonials.php to read real quotes from published authors.

Submit your manuscript here: http://www.dovepress.com/chronic-wound-care-management-and-research-journal 